\title{
Body size-density relationship for Mytilus edulis in an experimental food-regulated situation
}

\author{
Marianne Alunno-Bruscia ${ }^{1,{ }^{*}}$, Peter S. Petraitis ${ }^{2}$, Edwin Bourget $^{3}$ and Marcel Fréchette ${ }^{4}$ \\ 1 IFREMER, Laboratoire Conchylicole de Méditerranée, Chemin de Maguelone, F-34250 Palavas-les-Flots, \\ France \\ 2 Dept of Biology, Univ of Pennsylvania, Philadelphia, PA $19104-6018$, USA \\ ${ }^{3}$ Faculté des sciences et de génie, Pavillon Alexandre-Vachon, Univ. Laval, Québec, QC, Canada G1K 7P4 \\ ${ }^{4}$ Institut Maurice-Lamontagne, Ministère des Pêches et Océans Canada, C.P. 1000, Mont-Joli, QC, Canada G5H \\ $3 Z 4$.
}

*: Corresponding author : Marianne Alunno-Bruscia, email address : Marianne.Alunno.Bruscia@ifremer.fr

\begin{abstract}
:
We grew mussels (Mytilus edulis) under two different food regimes and eight population density levels to estimate the joint effects of density and biomass on their growth and survival and to determine the shape of the biomass-density $(B-N)$ relationship. Mussels were reared for 22 months, between December 1994 and October 1996, in 1-L experimental chambers supplied with natural seston. Growth in shell length, individual wet mass and ash free dry mass $(\mathrm{m})$ decreased with decreasing food availability and increasing population density. Survival was negatively correlated with density but did not differ significantly between food regimes during the first year. Variations in concentration of available food did not alter the effects of crowding on mussels, as judged from the slopes of the body size-density curves. The general patterns exhibited by $\mathrm{B}-\mathrm{N}$ curves were not consistent with expectations since we found 1) no classical competition-density (C-D) effect as reported in plants at intermediate competition levels, and 2) a slope of -0.648 for $\mathrm{m}-\mathrm{N}$ curves in both food regimes, which was higher than expected from self-thinning (ST) theory. This value does not support present fooddriven ST theory. This study introduces an unusual $\mathrm{m}-\mathrm{N}$ region which combines properties of both ST and C-D effect.
\end{abstract}

Body size is a fundamental biological characteristic, and the effects of body size scaling are well known (Peters 1983, Schmidt-Nielsen 1984, LaBarbera 1989, Marquet et al. 1990, West et al. 1997). In organisms with plastic morphological expression, particularly plants, the relationship between body size and population density has been described extensively (Harper 1977, Westoby 1984, White 1985). Because resource requirements for space or food usually increase with body size, average body size should depend on the number of individuals that can be supported in a given environment, and should decrease as a function of crowding. The result is a negative correlation between body size and population density, whose extreme expression is referred to as the self-thinning relationship, which is commonly expressed as $\mathrm{m}-\mathrm{k} 1 \mathrm{Ng}$, where $\mathrm{m}$ is mean individual mass and $\mathrm{N}$ is current population density (Yoda et al. 1963). Self-thinning (hereafter ST) occurs when growth of dominant individuals suppresses smaller individuals (White 1981, Westoby 1984). ST in plants has been studied and debated extensively (reviewed by Puntieri 1993). More recently, ST theory was applied to explain the intraspecific body size-density relationship in animal species encompassing a broad range of body sizes, such as insects (Begon et al. 1986, Latto 1994), marine invertebrates (Branch 1975, Hogarth 1985, Hughes and Griffiths 1988, Fréchette and Lefaivre 1990, Petraitis 1995a, Guiñez and Castilla 
1999) and fish (Grant and Kramer 1990, Elliott 1993, Grant 1993, Bohlin et al. 1994, Tonn et al. 1994, Armstrong 1997, Dunham and Vinyard 1997). ST patterns are studied from individual groups sampled repeatedly or from even-aged groups of same initial population density sampled sequentially through time. This allows to plot $m-N$ trajectories of groups through time.

A second pattern revealed from body size-density relationships is the competition-density effect (hereafter C-D effect; Shinozaki and Kira 1956, Hagihara 1999). The C-D effect is studied from the pattern of body size as a function of population density found at a given moment during stand development $(m-N$ curve). In situations where competition is absent, individual mass is independent of population density $(\gamma=0)$. If competition is present, however, individual mass decreases with population density. Growth may still occur, but at reduced rate. This causes $\gamma$ to tend progressively toward -1 as competition becomes harsher. The $\mathrm{C}-\mathrm{D}$ effect occurs in situations where $\gamma=-1$ in $m-N$ curves. Although the theory of the C-D effect originally included only situations with no mortality (Shinozaki and Kira 1956), recent developments include both cases, with and without mortality (Xue and Hagihara 1998, Hagihara 1999).

Instead of plotting individual mass as a function of population density, it may be preferred to plot stand biomass as a function of population density. The resulting biomass-density relationship ( $B-N$ curve) is an equivalent formulation to the conventional relationship between body mass and population density $\left(B=k_{1} N^{\beta}, \beta=\gamma+1\right) \quad$ (Westoby 1984, Petraitis 1995b). Fig. 1 depicts a hypothetical $B-N$ curve, in which two distinct regions may be identified, depending on whether competition occurs or not (Westoby 1984). The first region, where competition is negligible at small values of $N$, represents biomass/density-independent individual growth and survival. Biomass increases with population density, and the slope of the $B-N$ curve is positive and constant across the various values of $N$. In the second region, individual growth decreases proportionally to population density and as the $\mathrm{C}-\mathrm{D}$ effect is approached, $\beta$ decreases. $B-N$ curves have been suggested to be useful in analysing the relative importance of competition-independent and -dependent mortality (Westoby 1984), identifying factors regulating populations (Norberg 1988, Fréchette and Lefaivre 1990) and managing plants (Westoby 1984) and cultured bivalves (Fréchette et al. 1996). However, studies of $B-N$ curves in animals have focused on the ST region (Hughes and Griffiths 1988, Fréchette and Lefaivre 1990, Fréchette et al. 1992, 1996, Elliott 1993, Latto 1994), and little is known on the general shape of $B-N$ curves for animal populations. In plants, however, $B-N$ curves exhibit an extensive horizontal region at intermediate competition levels, the classical C-D effect (e.g. Westoby 1984). The question of whether the C-D effect also exists in animals, and more specifically in molluscs, has not been fully addressed. Recent $B-N$ curves modelled from hypothetical mussel populations did not show a region of constant yield, but instead exhibited a curvilinear pattern (Fréchette and Bacher 1998). In addition, recent accounts of ST in animals (e.g. Fréchette and Lefaivre 1990, Elliott 1993, Bohlin et al. 1994, Latto 1994, Armstrong 1997) failed to provide a clear pattern of the ST function. Experimental studies of the actual shape of $B-N$ curves in molluscs are still lacking.

Here we report the results of an experimental study on the influence of stocking density and food concentration on growth and survival of Mytilus edulis. Mussel growth was assumed to be regulated by food availability with no physical interference with conspecifics. In the laboratory, we submitted groups of $M$. edulis individuals to different food and population density combinations for extensive periods of time, and monitored individual growth and survival. We compared the $B-N$ curves obtained to those of the theoretical $B-N$ diagram expected in molluscs and plants, and examined whether ST occurred. Our analysis shows that present theory of food-driven ST in molluscs should be revised.

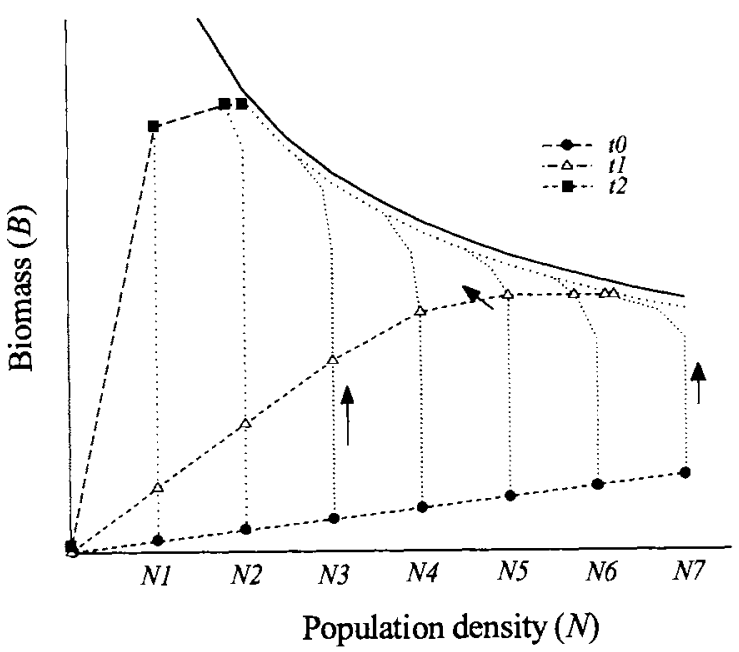

Fig. 1. Example of a typical $B-N$ diagram observed for several densities sampled over time. Initial density of groups varies from $N I$ to $N 7$. Successive sampling times are noted $t 0$, at the beginning of the experiment, to $t 2$. This type of diagram may be analysed in two ways. The first way is to analyse data points obtained for all densities at a given sampling time. The second way is to analyse the $B-N$ trajectory obtained for each separate density group over time. Arrows show direction of time. 


\section{Methods}

\section{Experimental design}

The laboratory experiment was carried out over a 22-month period, from mid-December 1994 until midOctober 1996, at the Maurice-Lamontagne Institute (Mont-Joli, Québec, Canada) on the south shore of the Lower St. Lawrence Estuary. A factorial design was used to assess the effect of food concentration and population density on the growth and survival of $M$. edulis. The experimental design involved two food levels (high vs low) and eight density levels $(8,16,24,40,48$, $64,72,80$ mussels per growth chamber, hereafter labelled $N 8, N 16, \ldots, N 80$ ) with two additional empty chambers $(N O)$ to monitor incoming food level. Each food $\times$ density cell contained three replicate chambers. Therefore, 120 identical 1-L plastic experimental chambers were stocked in December 1994 with a total of 4224 mussels (shell length $(L)$ range $=[19.0-21.0] \mathrm{mm}$ and average ash free dry mass $(m)=0.0374 \mathrm{~g} \pm 0.0076$ ) which were collected in October 1994 at Îles-de-laMadeleine, Québec, and were kept in running seawater until the beginning of the experiment. Half of the growth chambers were terminated in October 1995 and the other half in October 1996. Data from December 1994 to October 1995 and October 1995 to October 1996 were analysed separately.

Each chamber (11 cm diam., $14 \mathrm{~cm}$ high) contained two identical cylindrical Vexar cages $(10.2 \mathrm{~cm}$ diam., $4.5 \mathrm{~cm}$ high, $0.7 \mathrm{~cm}$ mesh). A total of 240 cages were randomly assigned an initial "up" or "down" position in each chamber at the beginning of the experiment. Their position was changed on a regular basis, every three months from late October to early May, and every five weeks from late May to early October. This procedure was done to eliminate the effect of the cage position on mussel growth. Two perpendicular polyethylene walls divided the two cages within each chamber into four identical cells. Within the cages, each cell was stocked with the same number of mussels, so that total densities in the growth chambers were 8,16 , $24,40,48,64,72$ and 80 . Dividing the mussels among cells within cages and cages within chambers minimized interference between individuals (Okamura 1986).

Growth chambers were supplied with natural seawater pumped from the nearby estuary and distributed from head tanks by gravity. Flow rates in the chambers were monitored every three days, and adjusted to $0.60 \pm 0.06 \mathrm{~L} \mathrm{~min}^{-1}$. It was assumed that the chambers were well mixed, though this assumption may not have been fully met (Epstein 1990). The chambers were cleaned weekly to remove sedimented materials, or whenever wind events resulted in significant amounts of resuspended sediments entering the chambers.

Mussels were fed two food concentrations: high food ( $\mathrm{HF}=100 \%$ of non-filtered seawater), corresponding to that observed in situ (typical ranges are given by Demers et al. 1987); low food ( $\mathrm{LF}=1 / 3 \mathrm{HF}$ ), which was achieved by mixing $\approx 30 \%$ non-filtered seawater with $\approx 70 \%$ filtered seawater in two head tanks. Filtered seawater was produced by filtering estuarine seawater through a $80-120-\mu \mathrm{m}$ mesh pressure sand filter. From late October to mid-May, only filtered seawater was available. During that period, mussels were fed dried Spirulina sp. (Spirulina Microfine, Argent Chemical Laboratories) twice a week. Spirulina sp. was resuspended and diluted in filtered seawater to obtain two concentrations, $1.00 \mathrm{~g} \mathrm{~L}^{-1}$ and $0.33 \mathrm{~g} \mathrm{~L}^{-1}$, respectively, for the high food and low food regimes. Water flow into the head tanks was stopped for $2 \mathrm{~h}$ to allow mussels to feed.

\section{Data collection}

Environmental variables were collected to characterize the conditions prevailing in each food treatment. Water temperature $\left( \pm 0.2^{\circ} \mathrm{C}\right)$ and salinity $( \pm 0.3)$ were recorded on a daily basis at $\approx 09: 00 \mathrm{~h}$ in the head tanks for both food treatments with a YSI probe (in 1995), and an ORION model 140 probe (in 1996). From mid-May to mid-October, the availability of food for mussels was estimated on a weekly basis in the 12 empty chambers by 1) fluorometry with a Turner Designs Model 10 fluorometer, and 2) filtration of particulate organic matter. Fluorescence readings were made on $1.2-\mathrm{mL}$ seawater samples which were extracted in $6.8 \mathrm{~mL}$ acetone for $24 \mathrm{~h}$ in the dark and then centrifuged (Phinney and Yentsch 1985). Fluorescence was blank-corrected with GF/C filtered seawater. Fluorescence, as measured here, provided an estimate of phytoplankton concentration. Samples of seston were collected on pre-combusted $\left(24 \mathrm{~h}\right.$ at $\left.450^{\circ} \mathrm{C}\right)$, preweighed Whatman GF/C filters. Filters were rinsed with isotonic ammonium formate to remove sea salts, frozen at $-18^{\circ} \mathrm{C}$ and subsequently analysed. After drying at $70^{\circ} \mathrm{C}$ for $4 \mathrm{~h}$, they were weighed to the nearest $0.0001 \mathrm{~g}$ with a Mettler AE 163 balance, then ashed at $450^{\circ} \mathrm{C}$ for $24 \mathrm{~h}$ and weighed again for the determination of particulate organic and inorganic matter (POM and PIM) (Fréchette and Grant 1991).

Observations on shell length, total fresh biomass, and number of living mussels were made on 12 sampling dates: 8-14 December 1994, 21-22 June 1995, 19-20 July 1995, 21-22 August 1995, 12-14 October 1995, 19 and 30-31 January 1996, 19-21 March 1996, 17-19 June 1996, 10-12 July 1996, 7-9 August 1996, 5-6 September 1996, and 1-2 October 1996. The shells of 1200 mussels were individually marked with a file at the beginning of the experiment. The number of marked mussels in each growth chamber varied with the stocking density, i.e. eight mussels at $N 8, N 16$ and $N 24$ and a quarter of the total number of mussels per chamber 
from $N 40$ to $N 80$. On each sampling date, byssal threads were cut gently using a scalpel prior to measuring shells. Marked mussels were individually measured for shell length ( $L, \mathrm{~mm}$, anteroposterior axis) with a vernier calliper to the nearest $0.1 \mathrm{~mm}$. Within each chamber, living mussels were counted whereas dead mussels were measured and removed. The total fresh biomass $(\mathrm{g})$ of living mussels in the chambers was weighed to the nearest $0.01 \mathrm{~g}$ on an electronic Mettler balance (PE 3600 and BB 2400 models) after blotting the mussels. Individual ash free dry mass (g) was determined in October 1995 by sacrificing mussels from half of the growth chambers, and in October 1996 by harvesting the other half of the remaining individuals. Mussels were frozen at $-18^{\circ} \mathrm{C}$ for later determination of tissue dry mass with a Mettler AE 163 balance to the nearest $0.0001 \mathrm{~g}$. Ash free dry mass was obtained by the difference between dry body mass measured after thawing, removing of byssus and drying at $70^{\circ} \mathrm{C}$ for $72 \mathrm{~h}$, and its ash mass after combustion at $450^{\circ} \mathrm{C}$ for $24 \mathrm{~h}$.

\section{Data analysis}

Environmental variables were compared between food treatments in 1995 and 1996 with paired $t$-tests (Sokal and Rohlf 1981, Underwood 1997). For water temperature and salinity, we tested the null hypothesis that $\mathrm{HF}=\mathrm{LF}$. For the measures of food level, i.e. fluorescence and seston concentration, we tested the null hypothesis for a paired $t$-test of $\mathrm{HF}=3 \mathrm{LF}$.

Comparisons of growth patterns for both food treatments were based on the individual shell length $(L)$, ash free dry mass $(m)$, and the average individual wet mass $(W M)$, and proceeded in two steps. Firstly, analysis of differences among initial average $L$ between chambers was done as a two-way ANOVA with density and food as fixed factors. Analysis of differences among final average $L$ between marked and unmarked mussels was carried out to test if the marking technique and the position of cages in the chamber had affected mussel shell growth. For this purpose, we used a nested five-way ANOVA with density, food, position of cages and mark as fixed factors and replicate nested within the combinations of density and food (Ruohonen 1998). Secondly, repeated measures analyses were conducted on shell length and average individual wet mass to test whether these variables varied with food concentration, density, and their interaction over time (von Ende 1993). As the sphericity assumption for the univariate repeated measures analysis was not met (Stevens 1986, Winer et al. 1991), we used the multivariate approach. Multivariate normality was assumed. In practice, ANOVAs and MANOVAs are generally recognized to be robust to departures from normality assumption in balanced designs (Box 1953, Lindman 1974, Underwood 1981). Except in extreme circumstances of marginal significance levels, one should take observed significance levels as guidelines for dealing with ANOVA assumptions rather than hard-and-fast decision rules (Hand and Taylor 1987). Thus, considering the highly significant probabilities associated with the $F$-ratio which were obtained in the present MANOVAs and the large amount of observations, it can be safely assumed that the validity of the test was not affected by possible violations of the assumptions required for the multivariate approach. Differences in average $W M$ among experimental food-density treatments were then tested by a three-way repeated measures analysis (MANOVA) with time as the "within-subject" factor, and food and density as the "between-subject" factors (fixed factors). Analysis for differences in $L$ among treatments was done using a four-way repeated measures MANOVA with time, food, and density as fixed factors and replicate nested in the combinations of food and density. A profile analysis allowed to identify the particular time intervals in which the treatment (i.e., food, density, and their interaction food $\times$ density) effects were different (Stevens 1986). Profile analyses of the time factor and the food $\times$ time and density $x$ time interactions are based on differences ("contrasts") of two adjacent sampling months. Individual ANOVAs ( $F$-test) were done on each of the $K-1$ contrasts, where $K$ is the number of sampling months (von Ende 1993).

Survival patterns over time were analysed through a failure-time analysis (Muenchow 1986, Fox 1993) to determine the effect of food and density on the time of mussel death. Failure-time analysis accommodates "censored" data corresponding to live mussels at the end of our experiment (Muenchow 1986). Survival curves were tested for homogeneity between the 16 food-density treatments by the SAS LIFETEST procedure (SAS 1989) using the log-rank test (Lee 1980). The LIFETEST procedure also allows to test for a linear relationship between survival time and density treatment.

To analyse growth and survival patterns, $B-N$ curves for each food treatment were constructed using the eight different densities and successive sampling dates, resulting in time trajectories for several density groups (see Fig. 1). Average individual $m$ in October 1995 and 1996 were plotted against $N$ ( $\ln -\ln$ data). The $m-N$ curves were estimated using a simple linear regression model for both food treatments in October 1995 and 1996, and slopes and elevations were tested (Sokal and Rohlf 1981). Finally, we compared the results for chambers terminated in October 1995 with Fréchette and Bacher's (1998) simulation of densitydependent growth for mussels, which assumed no interference between mussels. 


\section{Results}

\section{Environmental variables}

Sea water temperature averaged $1.3^{\circ} \mathrm{C}$ from early November to late April (extremes of -1.0 to $3.5^{\circ} \mathrm{C}$ ) and increased steadily from about $3^{\circ} \mathrm{C}$ in early May to about $12^{\circ} \mathrm{C}$ and $14^{\circ} \mathrm{C}$ in July, respectively, in the LF and $\mathrm{HF}$ treatments. Water temperature differed significantly between the HF and LF treatments, both in 1995 (paired $t$-test, $\Delta^{\circ} \mathrm{C}=0.51 \pm 0.07 \mathrm{SE}, t=7.12, \quad P<$ $0.001, n=362)$ and $1996\left(\Delta^{\circ} \mathrm{C}=0.73 \pm 0.06 \mathrm{SE}, t=\right.$ $11.55, P<0.001, n=328$ ), and was significantly higher in the HF than in the LF treatments. The differences mainly occurred between May and October, when LF condition was prepared by mixing non-filtered and filtered seawater. Non-filtered and filtered seawater was pumped, respectively, at $\approx 4 \mathrm{~m}$ and $\approx 18 \mathrm{~m}$ depth, resulting in significant differences in temperature, especially during the summer. Salinity fluctuated from 21.4 to 30.5 between 1995 and 1996, and averaged 26.1 $( \pm 1.6 \mathrm{SD})$ and $26.6( \pm 1.6 \mathrm{SD})$, respectively, for the $\mathrm{HF}$ and LF treatments in 1995, and $26.0( \pm 1.8 \mathrm{SD})$ and $26.5( \pm 1.6 \mathrm{SD})$, respectively, for the HF and LF treatments in 1996. Salinity differed significantly between the HF and LF treatments in $1995(\Delta=$ $-0.14 \pm 0.06 \mathrm{SE}, t=-2.44, P=0.016, n=352)$ and $1996(\Delta=-0.34 \pm 0.04 \mathrm{SE}, t=-7.94, P<0.001, n=$ $322)$.

Fluorescence levels recorded here were consistent with those measured in nearby estuarine waters (Fréchette and Bourget 1985, Fréchette and Grant 1991). Concentrations of particulate organic (POM) and inorganic $(P I M)$ matter were of the order of $1 \mathrm{mg}$ $\mathrm{L}^{-1}$, except on occasional windy or stormy days when $P O M$ concentrations as high as $4.7 \mathrm{mg} \mathrm{L}^{-1}$ and $P I M$ concentrations of $30 \mathrm{mg} \mathrm{L}^{-1}$ were observed. These results are consistent with the calm conditions and the very low background concentrations of suspended particles reported in the literature for the Lower St. Lawrence Estuary (Kranck 1979, Demers et al. 1987, Fréchette and Grant 1991). The ratio of food levels HF:LF treatments did not differ from expectations (i.e. $\mathrm{HF}=3 \mathrm{LF}$ ) for fluorescence in 1995 and 1996, for $P O M$ in 1995 and 1996, and for PIM in $1995(P>$ 0.05). In 1996, however, the condition $\mathrm{HF}=3 \mathrm{LF}$ was not met for $P I M\left(\Delta=0.01 \pm 3 \cdot 10^{-3} \mathrm{SE}, t=3.39, P=\right.$ $0.004, n=32$ ).

\section{Growth patterns}

Differences in initial size of mussels, the effect of marking of the shells and the initial position of cages within the growth chambers are possible confounding factors. We tested the effect of each. Firstly, a two-way ANOVA was carried out to determine whether initial shell length $(\bar{X}=20.3 \mathrm{~mm} \pm 0.6 \mathrm{SD})$ differed significantly among treatment cells at the beginning of the experiment. Results indicate no difference in mean initial length among treatment cells (food $x$ density interaction: $F_{7,1182}=0.55, P=0.795$ ). Secondly, shell growth of marked and unmarked mussels was examined to determine whether the marking method and the position of cages within chambers influenced shell growth. A five-way ANOVA was performed to examine the influence of food, density, chamber, position of cages and mark on shell growth in October 1995 and 1996. Results show no significant effect of mark on final shell length $\left(F_{6,29}=0.56, P=0.758\right.$, and $F_{6,30}=1.75, P=$ 0.144 , respectively, for mussels harvested in 1995 and 1996). We found no significant effect of the position of cages either in the middle of the experiment (October 1995: $\left.F_{7,44}=0.74, P=0.640\right)$ or at the end of the experiment (October 1996: $F_{7,40}=0.50, P=0.829$ ). Thus, we conclude that the position of cages within the chamber did not influence mussel shell growth during the experiment.

Average individual wet mass ( $W M$ ) varied significantly with food concentration and density over time (Fig. 2A), as shown by repeated measures MANOVAs (Table 1) and profile analyses. From December 1994 to October 1995, mussels gained fresh mass (Fig. 2A) as indicated by a highly significant time effect on $W M$ (Table 1). Mussel mass increment, however, differed over time among food treatments and also among density levels (food $\times$ time, density $\times$ time: $P<0.001$, Table 1). $W M$ was lower in the LF treatment when compared with the HF treatment (Fig. $2 \mathrm{~A}$ ) by $\approx 30 \%$ and $\approx 50 \%$, in October 1995 and 1996, respectively. $W M$ decreased noticeably with increasing population density, e.g. by $62.5 \%$ and $59.0 \%$ on average between $N 8$ and $N 80$, respectively, in the HF and LF treatments during 1996 (Fig. 2A). The three-way interaction time $\times$ food $\times$ density was significant (Table 1), except between December 1994 and June $1995(P=0.059)$, and between July and August $1995(P=0.052)$. This result means that $W M$ was greater in the HF treatment than in the LF treatment, but not for all density levels. In 1996, time influenced $W M$ significantly (Table 1), except between January and March $1996(P=0.051)$ when no growth in $W M$ was observed in the HF and in the LF treatments (Fig. 2A). Both food treatment and population density continued to influence $W M$ during 1996, as indicated by significant food $\times$ time and density $\times$ time interactions (Table 1). Individual ANOVAs on the 1996 contrasts, however, revealed that a significant difference in the change in $W M$ due to both food and density factors only occurred between March and June 1996 and between August and September 1996 $(P<0.050$, Fig. 2A). Indeed, growth in $W M$ slowed down slightly between June and September 1996, and even became negative at $N 24, N 40$ and $N 64$ in the LF treatment. Variations in $W M$ between June and July 
A $\quad \begin{array}{ll}N 24 & -N 72 \\ & \end{array}$
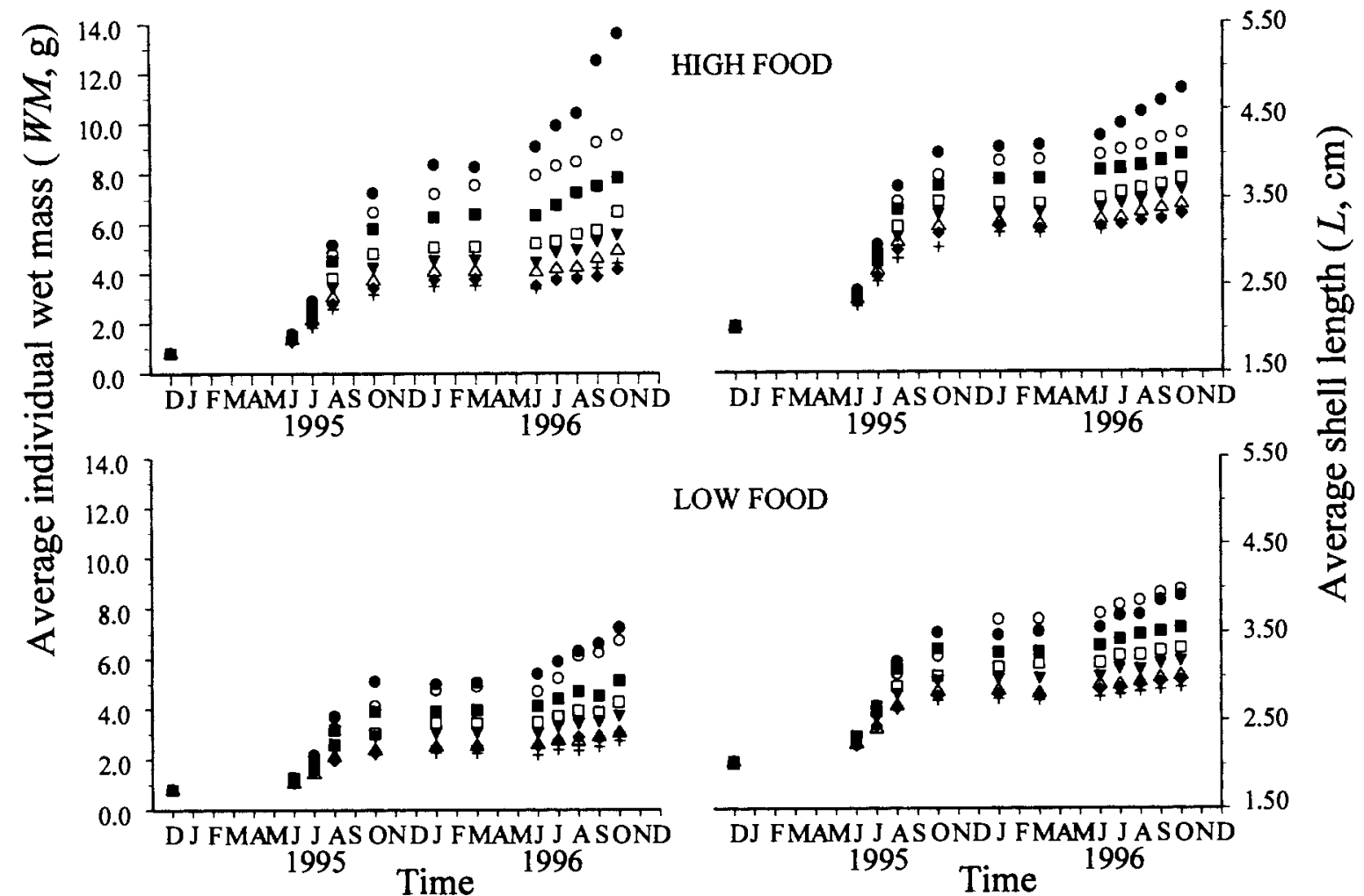

Fig. 2. Variations over time of the average individual wet mass ( $W M$, g; left panels) and the average shell length $(L, \mathrm{~mm}$; right panels) of Mytilus edulis held under two food regimes, i.e. high food and low food treatments, from December 1994 to October 1996.

1996, and between September and October 1996, although significant $(P<0.050)$, did not change with food treatments and density groups (time $\times$ food, time $\times$ density: $P>0.050$ ). The time $\times$ food $\times$ density interaction had no significant effect on $W M(P>$ 0.050), except between July and August $1996(P=$ $0.014)$ when the time $\times$ density interaction also influenced variations in $W M$. In short, variations of average individual wet mass over time were complex with no clear patterns emerging (Fig. 2A).

Mussel shell length $(L)$ also varied significantly with both food concentration and density over time (Fig. 2B) as indicated by repeated measures MANOVAs (Table 2) and profile analyses. Time had a significant effect on $L$ from December 1994 to October 1996 (Table 2). Variations in $L$, however, differed over time among food regimes (food $\times$ time: $P<0.001$, Table 2), except for August-October 1995 $(P=0.256)$, June-July $1996(P=0.080)$ and AugustSeptember $1996(P=0.132)$ time intervals, when $L$ did not change significantly with food treatment.
Variations in $L$ also changed over time between density levels (significant density $\times$ time interaction, Table 2). As for $W M$, average shell length decreased with increasing population density in both food treatments (Fig. 2B). The final maximum average shell length in the LF treatment was $39.8( \pm 0.7 \mathrm{SD})$ and $28.7 \mathrm{~mm}$ $( \pm 0.5 \mathrm{SD})$ at $N 16$ and $N 80$, respectively, and 47.4 $( \pm 0.4 \mathrm{SD})$ and $33.1 \mathrm{~mm}( \pm 0.6 \mathrm{SD})$ in the HF treatment at $N 8$ and $N 72$, respectively. The reduced food concentration limited mussel $L$ growth at every density level (Fig. 2B). As early as August 1995, the eight HF density groups became well differentiated in terms of average $L$, which spread over a $8.4-\mathrm{mm}$ interval. In contrast, differences in average $L$ among the eight LF density groups were restricted to an interval of $5.5 \mathrm{~mm}$. At the end of the experiment, $L$ growth in each density group was reduced by $11 \%$ on average in LF when compared with HF (Fig. 2B). No significant difference in the change in shell length due to the time $\times$ food $\times$ density interaction was observed (Table 2). 


\section{Survivorship}

Survival analysis shows that survival time differed significantly between food treatments in 1995 (log-rank $\chi^{2}=3.93, P=0.049$ ), and in 1996 (log-rank $\chi^{2}=4.77$, $P=0.029$ ). Moreover, survival time of mussels was negatively related to density in 1995 (log-rank $\chi^{2}=$ $31.95, P<0.001$ ) and $1996\left(\log\right.$-rank $\chi^{2}=34.80, P<$ 0.001 ), indicating that mussels at high densities died earlier than mussels at low densities. Significant differences in survival distributions occurred in 1995 (logrank $\chi^{2}=58.22, \quad P<0.001$ ) and 1996 (log-rank $\chi^{2}=92.44, P<0.001$ ) between the 16 food-density treatments.

Multiple-paired comparisons between the 16 different food-density treatments enabled to localize where differences in survival patterns occurred. The sequential Bonferroni procedure was used to control the familywise error rate. For the LF treatment, none of the 28 paired-density comparisons in 1995 and 1996 were significant indicating that survival patterns did not differ between density groups. For the HF treatment, only the $N 40-N 80$ paired-density comparison exhibited a significant adjusted $P$-value for the log-rank test $(P=$ 0.010 ) in 1995. In 1996, however, eight out of 28 density-paired comparisons in the HF treatment were significant $(N 8-N 80: P=0.042, N 16-N 64: P=0.019$, N16-N80: $P=0.015, N 40-N 72: P=0.015, N 48-N 64$ : $P=0.010, N 48-N 80: P=0.006, N 64-N 72: P=0.006$,
N72-N80: $P=0.006$ ), all involving high density levels, i.e. $N \geq 64$ mussels per chamber. This was related to the lower percent survival observed at high density than at low density. Significant paired-density comparisons were more frequent in 1996 than in 1995 for the HF treatment, suggesting that differences in survival distributions were becoming more pronounced over time. Finally, comparisons of survival distributions within the same density levels, but for HF and LF treatments were significant only in 1996 for $N 40$ (log-rank adjusted $P=0.004), N 72$ (log-rank adjusted $P=0.006$ ), and $N 80$ (log-rank adjusted $P=0.023$ ).

\section{$B-N$ and $m-N$ relationships}

The relationships between average total fresh biomass $(B)$ and density of living mussels $(N)$ obtained for the 12 sampling dates are shown in Fig. 3. For clarity, lines have been drawn through data points only for December 1994, July 1995, October 1995, July 1996 and October 1996. Except in December 1994, when the $B-N$ curve was described by a straight line, data points on each sampling date clustered along a curvilinear line tending toward an asymptote for $N>24$ (Fig. 3), indicating that individual growth decreased with increasing population density. Total fresh biomass was also affected by food concentration, and increases in $B$ were

Table 1. Repeated measures MANOVA on individual average wet mass $(W M, \mathrm{~g})$ in 1995 and 1996, with one within-subject (Time) and two between-subject (Food, Density) factors. Results of multivariate tests for the between- and within-subject factors and their related interactions. df, degrees of freedom; Num. df and Den. df, numerator and denominator degrees of freedom, respectively; MS, mean squares value; $F, F$-ratio; $P>F$, unadjusted probability.

1995 Tests of hypotheses for between-subject factors

\begin{tabular}{lrrrr}
\hline Source of variation & df & MS & $F$ & $P>F$ \\
Food & 1 & 5089.36 & 49.95 & $<0.001$ \\
Density & 6 & 3604.07 & 35.37 & $<0.001$ \\
Food $\times$ Density & 6 & 144.51 & 1.42 & 0.244 \\
Error & 27 & 101.90 &
\end{tabular}

Tests of hypotheses for within-subject factors

\begin{tabular}{|c|c|c|c|c|c|}
\hline Source of variation & Num. df & Den. df & Wilks' lambda statistic value & $F$ & $P>F$ \\
\hline Time & 4 & 27 & $5 \cdot 10^{-3}$ & 1364.94 & $<0.001$ \\
\hline Time $\times$ Food & 4 & 27 & 0.07 & 85.46 & $<0.001$ \\
\hline Time $\times$ Density & 28 & 99 & 0.02 & 7.31 & $<0.001$ \\
\hline Time $\times$ Food $\times$ Density & 28 & 99 & 0.21 & 1.88 & 0.013 \\
\hline 1996 & \multicolumn{5}{|c|}{ Tests of hypotheses for between-subject factors } \\
\hline Source of variation & & $\mathrm{df}$ & MS & $F$ & $P>F$ \\
\hline Food & & 1 & 30.83 & 326.94 & $<0.001$ \\
\hline Density & & 7 & 7.67 & 81.37 & $<0.001$ \\
\hline Food $\times$ Density & & 7 & 0.38 & 4.04 & 0.003 \\
\hline Error & & 30 & 0.09 & & \\
\hline
\end{tabular}

Tests of hypotheses for within-subject factors

\begin{tabular}{lcccrc} 
& Num. df & Den. df & Wilks' lambda statistic value & $F$ & $P>F$ \\
Time & 7 & 21 & $2 \cdot 10^{-3}$ & 1815.16 & $<0.001$ \\
Time $\times$ Food & 7 & 21 & 0.03 & 115.69 & $<0.001$ \\
Time $\times$ Density & 42 & 102 & $4.10^{-3}$ & 5.61 & $<0.001$ \\
Time $\times$ Food $\times$ Density & 42 & 102 & 0.09 & 1.67 & 0.019 \\
\hline
\end{tabular}


Table 2. Repeated measures MANOVA on shell length $(L, \mathrm{~mm})$ in 1995 and 1996, with one within-subject factor ( $=$ Time) and three between-subject factors (fixed factors = Food, Density; random factor = Replicate nested in the combination of Food and Density). Results of multivariate tests for the between- and within-subject factors and their related interactions. df, degrees of freedom; Num. df and Den. df, numerator and denominator degrees of freedom, respectively; MS, mean squares value; $F$, $F$-ratio; $P>F$, unadjusted probability. $F$-ratio of appropriate MS was calculated by specifying the appropriate error term $=$ Replicate $($ Food $\times$ Density) for Time $\times$ Food, Time $\times$ Density and Time $\times$ Food $\times$ Density interactions.

1995 Tests of hypotheses for between-subject factors

\begin{tabular}{lrrrr}
\hline Source of variation & $\mathrm{df}$ & MS & \multicolumn{1}{c}{} & $P>F$ \\
Food & 1 & 1935.71 & 210.30 & $<0.001$ \\
Density & 7 & 637.61 & 69.27 & $<0.001$ \\
Food $\times$ Density & 7 & 18.66 & 2.03 & 0.119 \\
Error & 15 & 9.20 & &
\end{tabular}

Tests of hypotheses for within-subject effects

\begin{tabular}{|c|c|c|c|c|c|}
\hline \multirow[b]{2}{*}{ Source of variation } & \\
\hline & Num. df & Den. df & $\begin{array}{l}\text { Wilks' lambda } \\
\text { statistic value }\end{array}$ & $F$ & $P>F$ \\
\hline Time & 4 & 475 & 0.04 & 2886.88 & $<0.001$ \\
\hline Time $\times$ Food & 4 & 12 & 0.04 & 79.23 & $<0.001$ \\
\hline Time $\times$ Density & 28 & 45 & $3 \cdot 10^{-3}$ & 6.19 & $<0.001$ \\
\hline Time $\times$ Food $\times$ Density & 28 & 45 & 0.10 & 1.42 & 0.145 \\
\hline 1996 & \multicolumn{5}{|c|}{ Tests of hypotheses for between-subject effects } \\
\hline Source of variation & & $\mathrm{df}$ & $\mathrm{MS}$ & & $P>F$ \\
\hline Food & & 1 & 10325.40 & 210.30 & $<0.001$ \\
\hline Density & & 7 & 4820.96 & 98.19 & $<0.001$ \\
\hline Food $\times$ Density & & 7 & 77.85 & 1.59 & 0.177 \\
\hline \multirow[t]{2}{*}{ Error } & & 31 & 49.10 & & \\
\hline & \multicolumn{5}{|c|}{ Tests of hypotheses for within-subjects effects } \\
\hline Source of variation & Num. df & Den. df & $\begin{array}{l}\text { Wilks' lambda } \\
\text { statistic value }\end{array}$ & $F$ & $P>F$ \\
\hline Time & 7 & 437 & 0.03 & 1879.19 & $<0.001$ \\
\hline Time $\times$ Food & 7 & 25 & 0.09 & 34.43 & $<0.001$ \\
\hline Time $\times$ Density & 49 & 131 & 0.01 & 4.12 & $<0.001$ \\
\hline Time $\times$ Food $\times$ Density & 49 & 131 & 0.19 & 1.02 & 0.453 \\
\hline
\end{tabular}

more pronounced for HF than LF mussels for any given density (Fig. 3). In October 1996, the maximum average total fresh biomass was $293 \mathrm{~g}$ for 68 mussels per chamber in the HF treatment, and $199 \mathrm{~g}$ for 74 mussels per chamber in the LF treatment.

The vertical $B-N$ trajectories obtained for each separate density group over time showed similar overall patterns and exhibited successively three distinct phases (Fig. 3). An initial increase in biomass occurred in both food treatments during the summer months of 1995 (June-October). This yielded vertical $B-N$ trajectories. Survivorship began to decline just after June 1995 and July 1995 in HF and LF treatments, respectively. For both food treatments, the decline in $N$ was greater in high than low density groups, and was initiated at $\approx 1.35 \mathrm{~g}$ average individual $W M$. A reduction in growth then followed during autumn and winter (October 1995-March 1996) as indicated by the proximity of data points while the number of mussels per chamber dropped significantly at $N 40, N 64$ and $N 80$ in the HF treatment, and at $N 48$ to $N 80$ in the LF treatment. Lastly, growth resumed during the second summer period (June-October 1996), though at a much smaller rate than during the first summer, with relatively constant $N$.

Average ash free dry mass clearly responded to food concentration and population density (Fig. 4). For any given density, $m$ was much higher at high food than at low food concentration and, irrespective of food treatment, $m$ was lower at high densities. Data points in 1995 and 1996 for $N \geq 24$ clustered to form two distinct clouds towards the lower right-hand side of the scattergram for each food treatment (Fig. 4). A three-way ANOVA with food, density and year as fixed factors and replicate nested in the combination food $\times$ density $\times$ year indicated that $m$ increased significantly between 1995 and 1996 in each density group $(P<0.001)$. Adjusted $m$ for the 16 food-density treatments was calculated by least-squares means analysis and were compared between years for each food-density level. Comparisonwise error rate for these 16 post-hoc tests was adjusted to a Bonferroni corrected $\alpha$ level of 0.003 $(=0.05 / 16)$. Except at $N 8$ in the HF treatment, adjusted $m$ did not differ significantly between years for each food-density level $(P>0.050)$. Therefore, we concluded that there was no individual growth in $m$ between 1995 and 1996 in these groups. We then eliminated groups with no mortality to meet ST assumptions. Significant regressions of $\ln (m)$ against $\ln (N)$ were obtained on each sampling year and in both food treatments for these groups (Table 3). Statistical comparison of regression lines between overall food treatments and years revealed that slopes were homogeneous with an adjusted common value of -0.648 
(Table 3). Elevations did not differ significantly between October 1995 and 1996 in the HF treatment, but were heterogeneous over year in the LF treatment $(P<0.001$, Table 3$)$.

We compared our 1995 results with those obtained from Fréchette and Bacher's simulation (1998) (Fig. 5). Fréchette and Bacher (1998) modelled growth of mussels over six months under the same specifications as our experiment, but imposed no mortality. The relationship between observed (our data, $m_{\mathrm{o}}$ ) and modelled (Fréchette and Bacher's data, $m_{\mathrm{M}}$ ) ash free dry mass in the HF treatment was: $m_{\mathrm{M}}=-0.043+0.791 m_{\mathrm{o}}$ (linear RMA regression, $r^{2}=0.958, N=24$ ). The slope was found to be significantly different from 1 ( $t$-test: $t=$ $5.405, P>0.050), m_{\mathrm{o}}$ increasing more rapidly than $m_{\mathrm{M}}$ (Fig. 5). In the LF treatment, however, a second-order polynomial model was adjusted to the relationship between observed and modeled $m: m_{\mathrm{M}}=-0.007+$ $0.550 m_{\mathrm{o}}-0.759 m_{\mathrm{o}}^{2}$ (MS residual $=5 \cdot 10^{-4}, P<0.001$, $N=24$ ). This relationship indicates a rather severe deviation of the modelled growth from the observed growth, particularly for large mussels, i.e. at low density (Fig. 5).

\section{Discussion}

The general patterns exhibited by $B-N$ and $m-N$ curves early in the experiment were consistent with theoretical expectations. At the start of the experiment, $B-N$ curves were linear as expected in situations where body size is not regulated by resource availability (Figs 1, 3). As of August 1995, the individual $B-N$ curves tended to an asymptote. However, the slope of the envelope of the $B-N$ curves decreased progressively with increasing population density, and shifted toward negative values at high densities $(N 72, N 80)$. At intermediate population densities, growth was reduced and became density dependent; curvilinearity appeared in the $B-N$ and $m-N$ curves. After a $\ln -\ln$ transformation, $m-N$ data still exhibited a subtle but significant curvilinear pattern with downward concavity. No significant growth in individual $m$ occurred between October 1995 and 1996 for both food treatments, except at $N 8$ for the HF treatment (Fig. 4). Since our mussels did not grow, their individual energy consumption and expenditure were apparently in equilibrium, thus meeting a necessary assumption of food-driven ST (FST, Fréchette and Lefaivre 1990).

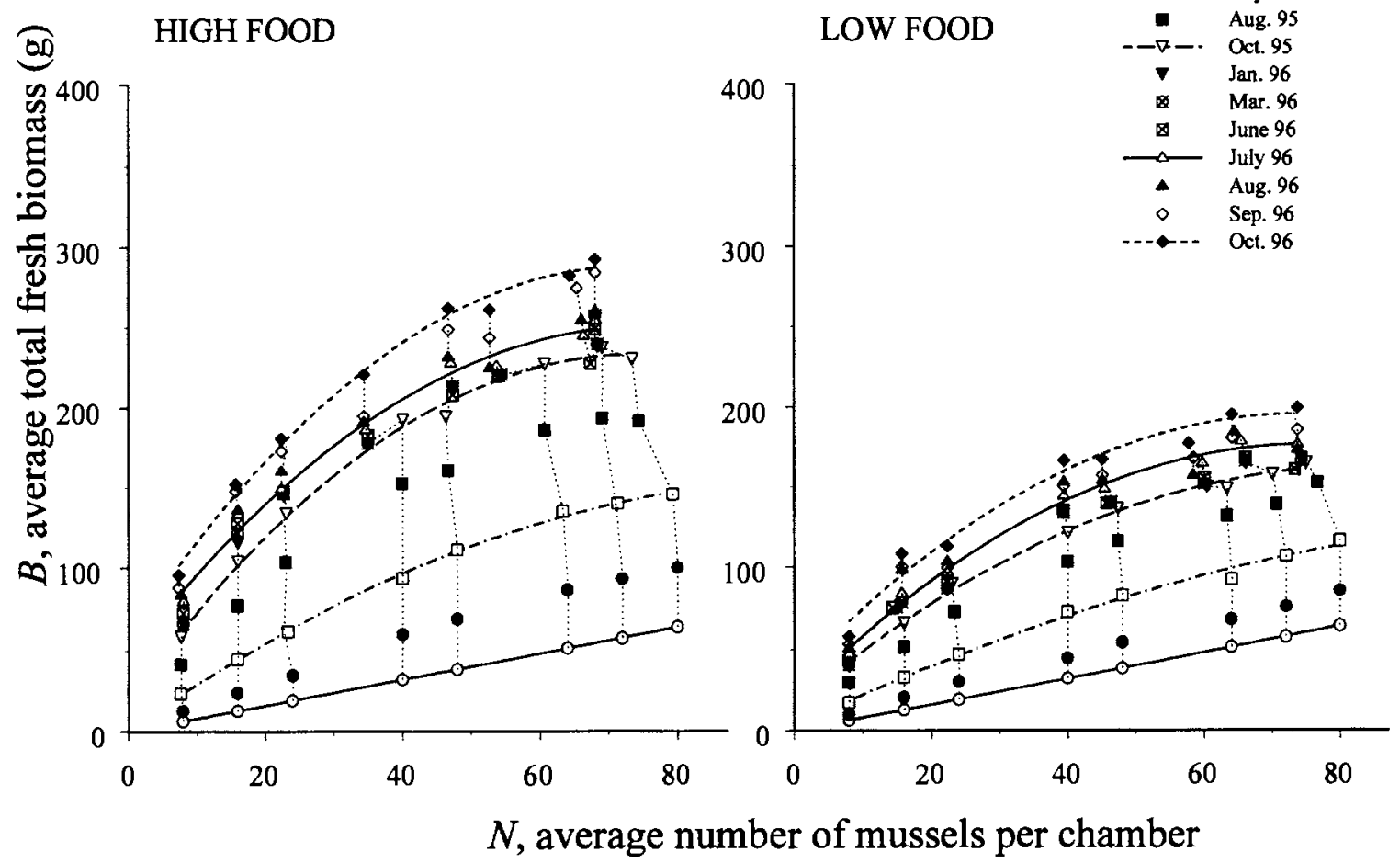

Fig. 3. Experimental $B-N$ diagram. Relationships between average number of mussels per chamber $(N)$ and average total fresh biomass $(B, \mathrm{~g})$ as a function of time and food treatment (high food and low food treatments). Solid curves in graphs represent polynomial curve fitted to data points obtained for all densities in December 1994, July 1995, October 1995 , July 1996 and October 1996. Dashed lines represent the trajectory obtained for each separate density group over time. Arrows indicate direction of time. 


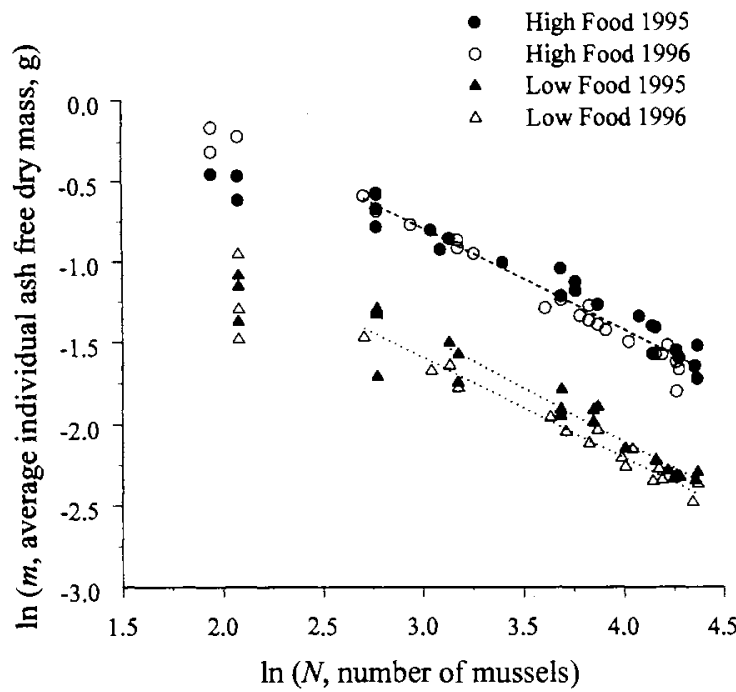

Fig. 4. Scattergram of $\ln (N$, number of mussels per chamber $)$ against $\ln (m$, average individual ash free dry mass per chamber, g) for $M$. edulis held under two experimental conditions, i.e. high food and low food treatments, from December 1994 to October 1996. Mussels were harvested in October 1995 and October 1996. Broken lines in graphs represent regression models fitted to density groups exhibiting no growth and mortality, for both food treatments and years, respectively (see statistics and equations in Tables 8, 9).

The basic assumption of FST is that individuals remove food until its concentration reaches a critical level below which metabolic demands can no longer be sustained. Under such conditions, population food acquisition and respiration are in equilibrium and individual growth within groups can only proceed at the expense of some mortality. Therefore, ST curves can be written as $m=\left(C_{\mathrm{t}} / a\right)^{1 / b} N^{(-1 / b)}$ where $C_{\mathrm{t}}=$ total food consumption of the population, and $a$ and $b$ are parameters relating respiration to individual biomass (Fréchette and Lefaivre 1990). Based on a $m-N$ slope of -0.648 (Fig. 4), and assuming that the model above is valid and that changes in population density among density groups are analogous to mortality, the required value for $b$ would equal 1.543 . This value is inconsistent with the overall mean exponent $b=0.70$ found in mol-

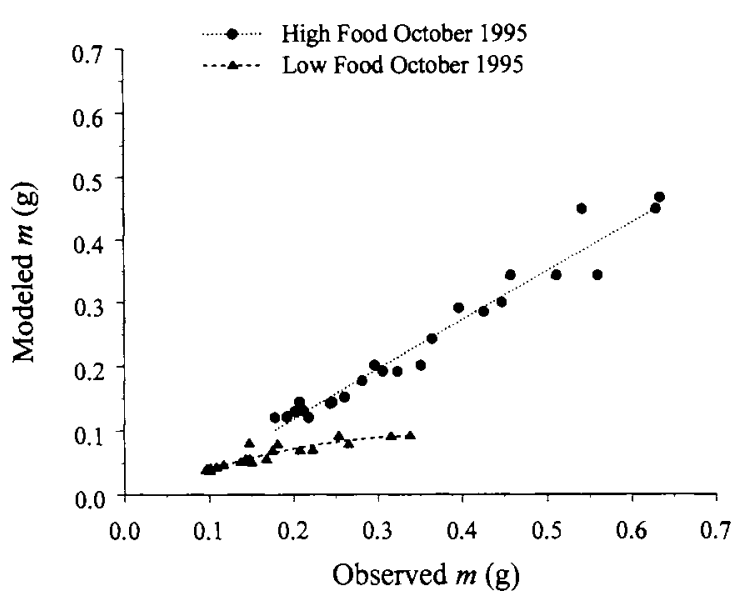

Fig. 5. Scattergram of observed (this study) against modelled (Fréchette and Bacher 1998) average individual ash free dry mass $(m, g)$ for $M$. edulis held under two experimental conditions, i.e. high food and low food treatments, and harvested in October 1995.

luscs (Bayne and Newell 1983) or $b=0.75$, as generally expected (West et al. 1997). It is also inconsistent with $b=0.87$, which was reported for adult starved $M$. edulis (Famme 1980). According to the FST model above, the thinning exponent expected from the value of $b=0.75$ should have been -1.33 (Damuth 1981, Fréchette and Lefaivre 1990, 1995), which is at odds with our slopes of -0.648 for the HF and LF treatments. Therefore, the basic assumptions for FST were apparently met, but the slope of the corresponding $m-N$ relationship differed significantly from expectations. Two explanations may account for this paradox.

It is possible that the mussels may actually have been undergoing ST. If this were the case, the assumptions of the FST model proposed by Fréchette and Lefaivre (1990) would appear to be insufficient. Thus, we suggest that Fréchette and Lefaivre's model should be revised and we caution against erroneous rejection of ST outcomes based on present ST theory. Food regulation might not be the only mechanism required to induce classical ST patterns. Although our experiment was designed to avoid interference between mussels, crowd-

Table 3. Ordinary least square regressions of natural logarithm of average ash free dry mass $(m, \mathrm{~g})$ against natural logarithm of population density $(N)$ for Mytilus edulis held under two food concentrations (high food vs low food) and harvested in October 1995 and 1996. Only density groups exhibiting no growth between 1995 and 1996, and mortality, were selected. Slopes and elevations of significant regressions were compared by analysis of variance and covariance, respectively. $r^{2}$, coefficient of determination; $F, F$-statistic; $N_{\mathrm{i}}$, sample size; ns, $P>0.05 ;{ }^{* *}, 0.01<P \leq 0.05 ;{ }^{* * *}, P<0.001$.

\begin{tabular}{|c|c|c|c|c|}
\hline Treatment per year & Regression & $r^{2}$ & $F$ & $N_{\mathrm{i}}$ \\
\hline HF October 1995 & $\ln (m)=-0.658 \ln (N)+1.299$ & 0.918 & $145.21 * * *$ & 15 \\
\hline HF October 1996 & $\begin{array}{l}\ln (m)=-0.655 \ln (N)+1.263 \\
\text { Slopes } \\
\text { Elevations }\end{array}$ & 0.811 & $\begin{array}{l}81.95^{* * *} \\
0.01 \mathrm{~ns} \\
0.33 \mathrm{~ns}\end{array}$ & 13 \\
\hline LF October 1995 & $\ln (m)=-0.704 \ln (N)+0.749$ & 0.968 & $268.35^{* * *}$ & 11 \\
\hline LF October 1996 & $\begin{array}{l}\ln (m)=-0.591 \ln (N)+0.221 \\
\text { Slopes } \\
\text { Elevations }\end{array}$ & 0.948 & $\begin{array}{l}200.89^{* * *} \\
3.32 \mathrm{~ns} \\
7.45^{* *}\end{array}$ & 13 \\
\hline
\end{tabular}


ing might have resulted in co-occurrence of exploitative and interference competition. Interference competition is usually inferred from shell deformity in mussels (Seed 1968, 1978, Brown et al. 1976, Bertness and Grosholz 1985), clams (Ohba 1956, Cigarría and Fernández 1998), and barnacles (Barnes and Powell 1950, Hogarth 1985) as a result of the pressure exerted by surrounding individuals. Other mechanisms of interference, however, may be more subtle than those implied by shell deformity. When mussels are physically close to one another, the external pressure exerted by neighbours may cause a reduction in valve gaping. Jørgensen et al. (1988) found that reduced gaping of the valves is accompanied by a retraction of the mantle edges and exhalant siphon and ultimately a reduction of the interfilament canals of the gills. This in turn causes a decline in the clearance rate and food uptake. All other things being equal, this would suppress growth. Laboratory experiments on pairs of individual mussels, however, suggest that small-scale depletion of food is a more plausible mechanism of asymmetric competition than reduced valve gaping (Fréchette and Despland 1999). The issue of identifying interference competition cannot be resolved directly with the present data. However, comparing our results to those from a modelling study by Fréchette and Bacher (1998), which included exploitative competition only, suggests that interference was probably negligible. Indeed, the relationship between modelled and observed growth in the HF treatment followed a straight line instead of changing with increased crowding (see below).

Alternatively, what we observed may have been some transient state between the density-independent region and the ST region, without a classical C-D effect. Our $B-N$ and $m-N$ curves (Figs 3,4) did not exhibit evidence of a $\mathrm{C}-\mathrm{D}$ effect as reported for plants at intermediate competition levels (Kira et al. 1953, Westoby 1984, Morris and Myerscough 1985). The reasons for the lack of a C-D effect are unclear. The region of constant yield may be too small or too ephemeral to be easily detected. Fréchette and Bacher (1998) also failed to detect a $\mathrm{C}-\mathrm{D}$ effect on simulated $B-N$ curves when mussel growth was modelled under conditions similar to our experimental situation. To our knowledge, only Hosomi's study (1985) reported a constant final average individual mass for Mytilus galloprovincialis, which he attributed to the $\mathrm{C}-\mathrm{D}$ effect. It is not clear, however, whether the mussels in Hosomi's study (1985) were food-regulated as ours were. Other factors, such as interference - competition for space - may account for his results. Hosomi's (1985) interpretation could have been biased by multilayering of individuais in the mussel bed (Guiñez and Castilla 1999). We conclude that with food regulation 1) there is no C-D effect in $M$. edulis as reported in plants, and 2) there is an unusual region with hybrid features. This region combines the properties of both $\mathrm{C}-\mathrm{D}$ effect and ST, but with a slope of -0.648 which is significantly different from that predicted by $\mathrm{C}-\mathrm{D}$ theory and by metabolism-regulated ST models in molluscs (Fréchette and Lefaivre 1990, 1995) and in plants (Enquist et al. 1998).

Discrepancies between experimental and modelled growth rates (Fréchette and Bacher 1998) were significant in both food regimes, but more severe for the LF than for the HF treatment (Fig. 5). The relationship between observed and modelled $m$ in the HF food treatment was linear suggesting that as crowding increased with population density, no effects other than those of the physiological parameters used in the modelling study (Fréchette and Bacher 1998) were required to explain mussel growth in our experiment (Fig. 5). This invalidates interference as a possible explanation for discrepancy between observed and modelled $m-N$ slopes in the HF treatment. Individual $m$ in our experiment was larger than modelled $m$ for both food treatments. A number of reasons may account for this. First, food concentration might have been higher in 1995 than in 1991, when the reference growth experiment used to calibrate the model parameters (Fréchette and Bacher 1998) was conducted. This possibility, however, cannot be tested because of lack of measurements of food availability in 1991. A second reason for higher growth in our experiment may be related to the origin of mussels. In the 1991 experiment, the mussels were obtained as spat from a mussel farm in Baie-desChaleurs, Québec, whereas in our experiment, the mussels originated from a fast-growing stock in Îles-de-la-Madeleine (Myrand 1990, Tremblay et al. 1998). Mussel populations in Baie-des-Chaleurs are typically a mixture of $M$. edulis and Mytilus trossulus (McDonald et al. 1991, Mallet and Carver 1995). The latter grows at a lower rate than the former. Therefore, it is likely that the growth rate modelled by Fréchette and Bacher (1998) was lower than in our experiment. Both explanations, however, cannot account for the difference between HF and LF mussels in Fig. 5. This may be attributable to physiological compensation (Bayne et al. 1993), a process not included explicitly in Fréchette and Bacher's model (1998). When faced with a food stress, mussels exhibit physiological compensation such that the available energy in seston is used more efficiently, resulting in increased growth. Physiological compensation was more likely to occur in the LF than in the HF environment, and more so at high than at low population density, thus accounting for the discrepancy between the LF and HF treatments and also for the nonlinear relationship between observed and modelled $m$ in the LF treatment. Actual measurements of physiological rates will be examined elsewhere (Alunno-Bruscia et al. unpubl.). Finally, there was no mortality in Fréchette and Bacher's (1998) model. In contrast, some of the groups in our experiment suffered significant mortality, especially at high $N$. Since mortality was linked to ST, death of mussels may have relaxed 
feeding pressure on available seston, allowing survivors to grow further. Thus, the mean size in the experiment would have tended to be larger than in the model. Mortality, however, is unlikely to account for smaller individual size in the model because its effect would have been more severe for smaller sizes (high density groups) than larger sizes (low density groups). This would have resulted in an upward (concave) curve, unlike those shown in Fig. 5. In summary, interference was likely negligible in our experiment, as expected in small groups of individuals (Okamura 1986), and apparently physiological compensation occurred, but only when density was high and presumably competition was extreme.

The dynamic interaction between mussels and their food may be inferred from the analysis of the different $B-N$ trajectories over time for each density examined (Fig. 3). Initially an increase in total living biomass and relatively constant numbers within cohorts were observed. Mussels gained mass while food was available at concentrations high enough to sustain growth. This occurred mainly in summertime (June-October 1995). Mortality, however, began to appear at densities higher than 40 mussels per chamber between June and August 1995, presumably in response to food depletion. A second phase marked by halted growth and a decline in the number of survivors at high densities occurred during winter when temperature was $<2^{\circ} \mathrm{C}$, and food supply was low. At low densities $(N \leqslant 24)$, growth stopped in winter but mortality was marginal, presumably because during the first summer phase mussels had stored more reserves at low than at high densities as confirmed by a tridimensional length-mass-density relationship (Alunno-Bruscia et al. in press). As soon as sufficient food was made available, either by the restoration of adequate environmental conditions, or by the decline in population number due to mortality, mussels gained mass, and shell growth proceeded further. Then, a new cycle marked by a second period of active growth and reduced mortality between June and October 1996 began, coinciding with the third phase of stepwise growth. It is likely that another phase of decreasing densities and reduced growth would have happened during the following winter if the experiment had been prolonged. Such alternate cycles with die-off followed by subsequent resumption of growth were previously observed (Elliott 1993, Tonn et al. 1994) and modelled (Scheffer et al. 1995) for fish cohorts. Our results suggest that these cycles may not be restricted to the fish-plankton system but may also fit the musselphytoplankton case. As soon as the basic conditions are met (food depletion and variance between individuals resulting in mortality), systems consisting of a single consumer cohort and its prey may exhibit a stepwise die-off and depressed growth response. Our results also provide a clear example of the effect of density-independent mortality factors - in the present case, winter and its associated low temperature and food concentration at the input of the 1-L chambers - interacting with density-dependent mechanisms - in the present case, food regulation (Andrewartha and Birch 1960, Peterson and Black 1988).

Intraspecific competition is considered to be a major source of mortality in mussels (Stiven and Kuenzler 1979, Griffiths and Hockey 1987, McGrorty et al. 1990, Richardson and Seed 1990). Consequently, ST patterns should be pervasive in mussel population dynamics. ST, however, has been reported only in a limited number of studies on musseis, e.g. Choromytilus meridionalis (Griffiths 1981, Griffiths and Hockey 1987), Perumytilus purpuratus (Guiñez and Castilla 1999), and M. edulis (Fréchette and Lefaivre 1990, Ardisson and Bourget 1991, Fréchette et al. 1996). During the process of ST in nature, the larger individuals are usually forced clear of the substratum (Griffiths and Hockey 1987, Richardson and Seed 1990; but see Fréchette and Lefaivre 1990, who suggested that food- and spacedriven ST may alternate seasonally on culture stakes). Once byssal attachment has been extended and weakened, these mussels are quickly removed from the population. In this case, ST is interpreted as a consequence of space-driven competition (Griffiths and Hockey 1987, Hughes and Griffiths 1988, Richardson and Seed 1990, Guiñez and Castilla 1999). In our experiment, however, mussels were confined in the growth chambers. Nevertheless, we found no evidence of interference from the interpretation of the relationship between observed and modelled $m$ (see above). In contrast, by controlling natural food availability and by eliminating factors such as predation, recruitment and interspecific interactions, we clearly established food-regulated mortality, even if it did not materialize as a classical ST curve (see Fréchette and Lefaivre 1995, and Enquist et al. 1998).

The amount of available food did not seem to modify the crowding patterns since $m-N$ slopes were not significantly different between high and low food concentrations (Fig. 4). Only elevations differed between both food treatments. The $m-N$ curves therefore provided clear patterns from which to assess whether mussels were regulated or limited by resources (Murray 1994). Moreover, survival analysis and examination of the shape of $B-N$ curves (Fig. 3) did not show any significant differences in the timing of ST between HF and LF treatments. Mussel populations at high food concentration grew faster than at low food concentration and moved along an upper biomass-density line, but the relationship between mortality and biomass accumulation was similar at both food levels. Thus, resource use and capacity of survivors to produce biomass were likely similar at different food concentrations, but the number of survivors for a given population biomass was lower when food was in short supply. In this regard, our $m-N$ lines seem to exhibit analogous fea- 
tures with thinning lines in plants. In plants, populations at different fertility levels would tend to follow parallel thinning lines which would be lower for low fertility populations (White and Harper 1970, Westoby 1984, Morris and Myerscough 1985). This suggests that in our experiment food availability would affect the intercept of the FST equation, $\left(C_{t} / a\right)^{1 / b}$, although our results did not support the ST slope prediction.

To our knowledge, this study is the first one to describe the overall shape of $B-N$ curves in mussels. Our findings are not consistent with expectations on $B-N$ curves widely described in plants and recently applied to molluscs. Indeed, we found (1) no classical $\mathrm{C}-\mathrm{D}$ effect, and (2) the slope of $m-N$ curves in fooddriven competition higher than expected from ST theory, although apparently the conditions for ST had been met. Hence, further studies are still needed to reformulate present modelling of FST, and to improve our understanding of the unusual region we identified. $B-N$ curves provide synthetic information about the nature of competitive processes regulating population dynamics (body size-density dependent growth and survival, and their interaction over time). Finally, reducing the food supply to populations of competing mussels does not lead to major changes in the way that mussels interact with each other.

Acknowledgements - We thank L. Girard, J. Quimper, S. Brulotte, P. Goudreau, D. Dransart, C. Forget, J. Hamel, C. Mékhadoun, L. Pagé, F. Seguin, E. Deloison, B. Chenard, J. Gagnon, M. Valois and $G$. Jean for their help in the field and laboratory. We are specially grateful to G. Daigle for assistance with statistical analyses. This paper benefited from helpful critical comments by B. Sainte-Marie. M. Alunno-Bruscia was supported by funding of CORPAQ (Conseil des Recherches en Pêche et en Agro-alimentaire du Québec), GIROQ (Groupe Interuniversitaire de Recherches Océanographiques du Québec) and Université Laval.

\section{References}

Alunno-Bruscia, M., Fréchette, M. and Bourget, E. Shell allometry and length-mass-density relationship for Mytilus edulis in an experimental food-regulated situation. - Mar. Ecol. Prog. Ser. (in press).

Andrewartha, H. G. and Birch, L. C. 1960. Some recent contributions to the study of the distribution and abundance of insects. - Annu. Rev. Entomol. 5: 219-242.

Ardisson, P.-L. and Bourget, E. 1991. Abundance, growth, and production estimation of the blue mussel Mytilus edulis on moored buoys in the Estuary and northwestern Gulf of St. Lawrence. - Can. J. Fish. Aquat. Sci. 48: $2408-2419$.

Armstrong, J. D. 1997. Self-thinning in juvenile sea trout and other salmonid fishes revisited. - J. Anim. Ecol. 66: 519 . 526.

Barnes, H. and Powell, H. T. 1950. The development, general morphology and subsequent elimination of barnacle populations, Balanus crenatus and B. balanoides, after a heavy initial settlement. - J. Anim. Ecol. 19: 175-179.

Bayne, B. L. and Newell, R. C. 1983. Physiological energetics of marine molluses. - In: Saleuddin, A. S. M. and Wilbur, K. M. (eds), The Mollusca. Academic Press, pp. 407-515.
Bayne, B. L., Iglesias, J. I. P., Hawkins, A. J. S. et al. 1993. Feeding behaviour of the mussel, Mytilus edulis: responses to variations in quantity and organic content of seston. J. Mar. Biol. Assoc. UK 73: 813-829.

Begon, M., Firbank, L. and Wall, R. 1986. Is there a self-thinning-rule for animal populations? - Oikos 46: 122-124.

Bertness, M. D. and Grosholz, E. 1985. Population dynamics of the ribbed mussel, Geukensia demissa: the costs and benefits of an aggregated distribution. - Oecologia 67 : 192-204.

Bohlin, T., Dellefors, C., Faremo, U. and Johlander, A. 1994. The energetic equivalence hypothesis and the relation between population density and body size in stream-living salmonids. - Am. Nat. 143: 478-493.

Box, G. E. P. 1953. Non-normality and tests of variances. Biometrika 40: 318-335.

Branch, G. M. 1975. Intraspecific competition in Patella cochlear Born. - J. Anim. Ecol. 44: 263-281.

Brown, R. A., Seed, R, and O'Connor, R. J. 1976. A comparison of relative growth in Cerastoderma $(=$ Cardium $)$ edule, Modiolus modiolus, and Mytilus edulis (Mollusca: Bivalvia). - J. Zool. 179: 297-315.

Cigarría, J. and Fernández, J. 1998. Manila clam (Ruditapes philippinarum) culture in oyster bags: influence of density on survival, growth and biometric relationships. - J. Mar. Biol. Assoc. UK 78: 551-560.

Damuth, J. 1981. Population density and body size in mammals. - Nature 290: 699-700.

Demers, S., Therriault, J.-C., Bourget, E. and Bah, A. 1987. Resuspension in the shallow sublittoral zone of macrotidal estuarine environment: wind influence. - Limnol. Oceanogr. 32: 327-339.

Dunham, J. B. and Vinyard, G. L. 1997. Relationships between body-mass, population density, and the self-thinning rule in stream-living salmonids. - Can. J. Fish. Aquat. Sci. 54: $1025-1030$.

Elliott, J. M. 1993. The self-thinning rule applied to juvenile sea-trout, Salmo trutta. - J. Anim. Ecol. 62: 371-379.

Enquist, B. J., Brown, J. H. and West, G. B. 1998. Allometric scaling of plant energetics and population density. - Nature 395: 163-165.

Epstein, I. R. 1990. Shaken, stirred-but not mixed. - Nature 346: $16-17$

Famme, P. 1980. Oxygen-dependence of the respiration by the mussel Mytilus edulis L. as a function of size. - Comp. Biochem. Phys. A 67: 171-174.

Fox, G. A. 1993. Failure-time analysis: emergence, fowering, survivorship, and other waiting times. - In: Scheiner, S. M. and Gurevitch, J. (eds), Design and analysis of ecological experiments. Chapman and Hall, pp. 253-289.

Fréchette, M. and Bourget, E. 1985. Food-limited growth of Mytilus edulis L. in relation to the benthic boundary layer. - Can. J. Fish. Aquat. Sci. 42: 1166-1170.

Fréchette, M. and Lefaivre, D. 1990. Discriminating between food and space limitation in benthic suspension feeders using self-thinning relationships. - Mar. Ecol. Prog. Ser. 65: $15-23$.

Fréchette, M. and Grant, J. 1991. An in situ estimation of the effect of wind-driven resuspension on the growth of the mussel Mytilus edulis L. - J. Exp. Mar. Biol. Ecol. 148: 201-213.

Fréchette, M. and Lefaivre, D. 1995. On self-thinning in animals. - Oikos 73: 425-428.

Fréchette, M. and Bacher, C. 1998. A simulation study of body size relationships in food regulated experimental mussel populations. - J. Exp. Mar. Biol. Ecol. 219: 241-255.

Fréchette, M. and Despland, E. 1999. Impaired shell gaping and food depletion as mechanisms of asymmetric competition in mussels. - Écoscience 6: 1-11.

Fréchette, M., Aitken, A. E. and Pagé, L. 1992. Interdependence of food and space limitation of a benthic suspension feeder: consequences for self-thinning relationships. - Mar. Ecol. Prog. Ser. 83: 55-62. 
Fréchette, M., Bergeron, P. and Gagnon, P. 1996. On the use of self-thinning relationships in stocking experiments. Aquaculture 145: 91-112.

Grant, J. W. A. 1993. Self-thinning in stream-dwelling salmonids. - In: Gibson, R. J. and Cutting, R. E. (eds), Production of juvenile Atlantic salmon, Salmo salar, in natural waters. Can. Spec. Publ. Fish. Aquat. Sci,, pp. 99-102.

Grant, J. W. A. and Kramer, D. L. 1990. Territory size as a predictor of the upper limit to population density of juvenile salmonids in streams. - Can. J. Fish. Aquat. Sci. 47: 1724-1737.

Griffiths, C. L. and Hockey, P. A. R. 1987. A model describing the interactive roles of predation, competition and tidal elevation in structuring mussel populations. - S. Afr. J. Mar. Sci. 5: $547-556$.

Griffiths, R. J. 1981. Population dynamics and growth of the bivalve Choromytilus meridionalis $(\mathrm{Kr}$.) at different tidal levels. - Estuarine Coastal Shelf Sci. 12: 101-118.

Guiñez, R. E. and Castilla, J. C. 1999. A tridimensional self-thinning model for multilayered intertidal mussels. Am. Nat. 154: 341-357.

Hagihara, A. 1999. Theoretical considerations on the C-D effect in self-thinning plant populations. - Res. Popul. Ecol. 41: 151-159.

Hand, D. J. and Taylor, C. C. 1987. Multivariate analysis of variance and repeated measures. - Chapman and Hall.

Harper, J. L. 1977. Population biology of plants. - Academic Press.

Hogarth, P. J. 1985. Population density, mean weight, and the nature of the "thinning line" in Semibalanus balanoides (L.) (Cirripeda thoracica). - Crustaceana 49: 215-219.

Hosomi, A. 1985. On the persistent trend of constant biomass and the constant total occupation area of the mussel Mytilus galloprovincialis (Lamarck). - Venus Jpn. J. Malacol. (Kairuigaku Zasshi) 44: 33-48.

Hughes, R. N. and Griffiths, C. L. 1988. Self-thinning in barnacles and mussels: the geometry of packing. - Am. Nat. 132: 484-491.

Jørgensen, C. B., Laren, P. S., Møhlenberg, F. and Riisgård, H. U. 1988. The mussel pump: properties and modelling. Mar. Ecol. Prog. Ser. 45: 205-216.

Kira, T., Ogawa, H. and Sakazaki, N. 1953. Intraspecific competition among higher plants. I. Competition-yielddensity interrelationship in regularly dispersed populations. - J. Biol. Osaka City Univ. 4: 1-16.

Kranck, K. 1979. Dynamics and distribution of suspended particulate matter in the St. Lawrence Estuary. - Nat. Can. 106: 163-173.

LaBarbera, M. 1989. Analyzing body size as a factor in ecology and evolution. - Annu. Rev. Ecol. Syst. 20: 97117

Latto, J. 1994. Evidence for a self-thinning rule in animals. Oikos 69: $531-534$

Lee, E. T. 1980. Statistical methods for survival data analysis - Lifetime Learning Publications, Belmont, CA.

Lindman, H. R. 1974. Analysis of variance in complex experimental designs. - Freeman.

Mallet, A. L. and Carver, C. E. A. 1995. Comparative growth and survival of Mytilus trossulus and Mytilus edulis in Atlantic Canada. - Can. J. Fish. Aquat. Sci. 52: 18731880.

Marquet, P. A., Navarrete, S. A. and Castilla, J. C. 1990 Scaling population density to body size in rocky intertidal communities. - Science 250: 1125-1127.

McDonald, J. H., Seed, R. and Koehn, R. K. 1991. Allozymes and morphometric characters of three species of Mytilus in the Northern and Southern Hemispheres. - Mar. Biol. 111: $323-333$.

McGrorty, S., Clarke, R. T., Reading, C. J. and Goss-Custard, J. D. 1990. Population dynamics of the mussel Mytilus edulis: density changes and regulation of the population in the Exe estuary, Devon. - Mar. Ecol. Prog. Ser. 67: $157-169$.
Morris, E. C. and Myerscough, P. J. 1985. Effects of nutrient level on thinning and non-thinning crowding in even-aged populations of subterranean clover. - Aust. J. Ecol. 10: $469-479$.

Muenchow, G. 1986. Ecological use of failure time analysis. Ecology 67: 246-250.

Murray, B. G. 1994. On density-dependence. - Oikos 59: $520-523$.

Myrand, B. 1990. Can we increase mussel (Mytilus edulis) production in the Magdalen Islands (Québec, Canada) by better use of local stock-site combinations? - Bull. Aquacult. Assoc. Can. 90: 72-74

Norberg, A. 1988. Self-thinning of plant populations dictated by packing density and individual growth geometry and relationships between animal population density and body mass governed by metabolic rate. - In: Ebenman, B. and Persson, L. (eds), Size-structured populations: ecology and evolution. Springer-Verlag, pp. 259-279.

Ohba, S. 1956. Effects of population density on mortality and growth in an experimental culture of bivalve, Venerupis semidecussata. - Biol. J. Okayama Univ. 2: 169-173.

Okamura, B. 1986. Group living and the effects of spatial position in aggregations of Mytilus edulis. - Oecologia 69: 341-347.

Peters, R. H. 1983. The ecological implications of body size. Cambridge Univ. Press.

Peterson, C. H. and Black, R. 1988. Density-dependent mortality caused by physical stress interacting with biotic history. - Am. Nat. 131: 257-270.

Petraitis, P. S. 1995a. The role of growth in maintaining spatial dominance by mussels (Mytilus edulis). - Ecology 76: $1337-1346$.

Petraitis, P. S. 1995b. Use of average vs. total biomass in self-thinning relationships. - Ecology 76: 656-658.

Phinney, D. A. and Yentsch, C. S. 1985. A novel phytoplankton chlorophyll technique: toward automated analysis. - J. Plankton Res. 7: 633-642.

Puntieri, J. G. 1993. The self-thinning rule: bibliography revision. - Preslia Praha 65: 243-267.

Richardson, C. A. and Seed, R. 1990. Predictions of mussel (Mytilus edulis) biomass on an offshore platform from single population samples. - Biofouling 2: 289-297.

Ruohonen, K. 1998. Individual measurements and nested designs in aquaculture experiments: a simulation study. Aquaculture 165: 149-157.

SAS. 1989. SAS/STAT user's guide. Release $6.12 \mathrm{ed}$ - SAS Institute, Cary, NC.

Scheffer, M., Baveco, J. M., DeAngelis, D. L. et al. 1995. Stunted growth and stepwise die-off in animal cohorts. Am. Nat. 145: 377-388.

Schmidt-Neilsen, K. 1984. Scaling: why is animal size so important? - Cambridge Univ. Press.

Seed, R. 1968. Factors influencing shell shape in the mussel Mytilus edulis. - J. Mar. Biol. Assoc. UK 48: 561-584.

Seed, R. 1978. The systematics and evolution of Mytilus galloprovincialis Lmk. - In: Battaglia, B. and Beardmore, J. (eds), Marine organisms: genetics, ecology and evolution. Plenum Press, pp. 447-468.

Shinozaki, K. and Kira, T. 1956. Intraspecific competition among higher plants. VII. Logistic theory of the C-D effect. - J. Biol. Osaka City Univ, 7: 35-72.

Sokal, R. R. and Rohlf, F. J. 1981. Biometry, 3rd ed. Freeman.

Stevens, J. 1986. Applied multivariate statistics for the social sciences. - Lawrence Erlbaum.

Stiven, A. E. and Kuenzler, E. J. 1979. The response of two molluscs, Littorina irrorata and Geukensia demissa, to field manipulations of density and Spartina litter. - Ecol. Monogr. 49: $151-171$.

Tonn, W. M., Holopainen, I. J. and Paszkowski, C. A. 1994 Density-dependent effects and the regulation of crucian carp populations in single-species ponds. - Ecology 75: $824-834$ 
Tremblay, R., Myrand, B., Sévigny, J.-M. et al. 1998. Bioenergetic and genetic parameters in relation to susceptibility of blue mussels, Mytilus edulis (L.) to summer mortality. J. Exp. Mar. Biol. Ecol. 221: 27-58.

Underwood, A. J. 1981. Techniques of analysis of variance in experimental marine biology and ecology. - Oceanogr. Mar. Biol. Annu. Rev. 19: 513-605.

Underwood, A. J. 1997. Experiments in ecology: their logical design and interpretation using analysis of variance. Cambridge Univ. Press.

von Ende, C. N. 1993. Repeated-measures analysis: growth and other time-dependent measures. - In: Scheiner, S. M. and Gurevitch, J. (eds), Design and analysis of ecological experiments. Chapman and Hall, pp. 113-137.

West, G. B., Brown, J. H. and Enquist, B. J. 1997. A general model for the origin of allometric scaling laws in biology. - Science 276: 122-126.

Westoby, M. 1984. The self-thinning rule. - Adv. Ecol. Res. 14: $167-225$.
White, J. 1981. The allometric interpretation of the self-thinning rule. - J. Theor. Biol. 89: 475-500.

White, J. 1985. The thinning rule and its application to mixtures of plant populations. - In: White, J. (ed.), Studies in plant demography. A festschrift for John L. Harper. Academic Press, pp. 291-309.

White, J. and Harper, J. L. 1970. Correlated changes in plant size and number in plant populations. - J. Ecol. 58: 467-485.

Winer, B. J., Brown, D. R. and Michels, K. M. 1991. Statistical principles in experimental design. - McGraw-Hill.

Xue, L. and Hagihara, A. 1998. Growth analysis of the self-thinning stands of Pinus densiflora Sieb. et Zucc. Ecol. Res. 13: 183-191.

Yoda, K., Kira, T., Ogawa, H. and Hozumi, K. 1963. Selfthinning in over-crowded pure stands under cultivated and natural conditions (Intraspecific competition among higher plants XI). - J. Biol. Osaka City Univ. 14: 107-129. 